\title{
An epidemiological survey of bovine Babesia and Theileria parasites in cattle, buffaloes,
}

and sheep in Egypt

Ahmed Elsify ${ }^{\text {a,b }}$, Thillaiampalam Sivakumar ${ }^{\text {a }}$, Mohammed Nayel ${ }^{\text {b }}$, Akram Salama ${ }^{\text {b, }}$ Ahmed

Elkhtam $^{\mathrm{c}}$, Mohamed Rizk ${ }^{\mathrm{a}, \mathrm{d}}$, Omar Mosaab ${ }^{\mathrm{e}}$, Khaled Sultan ${ }^{\mathrm{f}}$, Shimaa Elsayed ${ }^{\mathrm{a}, \mathrm{g}}$, Ikuo Igarashi $^{\text {a }}$, Naoaki Yokoyama ${ }^{\mathrm{a}, *}$

${ }^{a}$ National Research Center for Protozoan Diseases, Obihiro University of Agriculture and Veterinary Medicine, Inada-cho, Obihiro, Hokkaido 080-8555, Japan

${ }^{\mathrm{b}}$ Department of Animal Medicine and Infectious Diseases, Faculty of Veterinary Medicine, University of Sadat City, Menoufia 32897, Egypt

${ }^{\mathrm{c}}$ Department of Parasitology, Faculty of Veterinary Medicine, University of Sadat City, Menoufia 32897, Egypt

${ }^{\mathrm{d}}$ Department of Internal Medicine and Infectious Diseases, Faculty of Veterinary Medicine, Mansoura University, Mansoura 35516, Egypt

${ }^{\mathrm{e}}$ Department of Parasitology, Faculty of Veterinary medicine, South-Valley University, Qena 83523, Egypt

${ }^{\mathrm{f}}$ Department of Parasitology, Faculty of Veterinary Medicine, Kafrelsheikh University, Kafr El-Sheikh 33516, Egypt

${ }^{\mathrm{g}}$ Department of Biochemistry and Chemistry of nutrition, Faculty of Veterinary Medicine, Mansoura University, Mansoura 35516, Egypt

*Corresponding author: Naoaki Yokoyama

National Research Center for Protozoan Diseases, Obihiro University of Agriculture and Veterinary Medicine, Inada-cho, Obihiro, Hokkaido 080-8555, Japan 
Tel.: +81-155-49-5649; Fax: +81-155-49-5643; E-mail: yokoyama@obihiro.ac.jp 


\section{ABSTRACT}

Cattle, buffaloes, and sheep are the main sources of meat and milk in Egypt, but their productivity is thought be greatly reduced by hemoprotozoan parasitic diseases. In this study, we analyzed the infection rates of Babesia bovis, B. bigemina, Theileria annulata, and $T$. orientalis, using parasite-specific PCR assays in blood-DNA samples sourced from cattle $(n=439)$, buffaloes $(n=50)$, and sheep $(n=105)$ reared in Menoufia, Behera, Giza, and Sohag provinces of Egypt. In cattle, the positive rates of B. bovis, B. bigemina, T. annulata, and $T$. orientalis were $3.18 \%, 7.97 \%, 9.56 \%$, and $0.68 \%$, respectively. On the other hand, B. bovis and $T$. orientalis were the only parasites detected in buffaloes and each of these parasites was only found in two individual DNA samples (both $2 \%)$, while one $(0.95 \%)$ and two $(1.90 \%)$ of the sheep samples were positive for B. bovis and B. bigemina, respectively. Sequence analysis showed that the B. bovis Rhoptry Associated Protein-1 and the B. bigemina Apical Membrane Antigen-1 genes were highly conserved among the samples, with $99.3-100 \%$ and 95.3-100\% sequence identity values, respectively. In contrast, the Egyptian T. annulata Merozoite Surface Antigen-1 gene sequences were relatively diverse (87.8-100\% identity values), dispersing themselves across several clades in the phylogenetic tree containing sequences from other countries. Additionally, the T. orientalis Major Piroplasm Surface Protein (MPSP) gene sequences were classified as types 1 and 2. This is the first report of $T$. orientalis in Egypt, and of type 2 MPSP in buffaloes. Detection of MPSP type 2, which is considered a relatively virulent genotype, suggests that $T$. orientalis infection may have veterinary and economic significance in Egypt. In conclusion, the present study, which analyzed multiple species of Babesia and Theileria parasites in different livestock animals, may shed an additional light on the epidemiology of hemoprotozoan parasites in Egypt. 
Key words: Babesia, Egypt, livestock, PCR, Theileria. 


\section{Introduction}

Piroplasmosis caused by different species of Babesia and Theileria in various wild and domestic animals affects the health status of the infected hosts [1]. Disease outbreaks in livestock animals related to infections with these parasites are of great economic significance. Among the Babesia species associated with bovine babesiosis, Babesia bovis, B. bigemina, and $B$. divergens are considered the most virulent [2]. While B. bovis and B. bigemina are found in tropical and subtropical regions of world, $B$. divergens, which is also defined as a zoonotic agent, is common in Europe [2,3]. Babesia sporozoites released from infected ticks during blood feeding infect the host's red blood cells (RBCs), where they transform into merozoites [4]. The asexual multiplication of merozoites within the RBCs results in hemolysis of the cells, leading to anemia and jaundice in a host animal [2]. The clinical picture associated with $B$. bovis infection includes nervous and respiratory symptoms caused by the sequestration of infected RBCs in the capillary beds of vital internal organs [5].

In cattle, T. parva and T. annulata are the main etiological agents of severe clinical theileriosis [6], but $T$. orientalis, a benign Theileria parasite, has also caused outbreaks of Theileriosis in several countries [7,8]. In contrast to most Babesia species, Theileria sporozoites infect the host leukocytes, where they undergo schizogony and merogony $[4,6]$. Because T. parva and T. annulata schizonts induce rapid proliferation of leukocytes, these species are classified as transforming Theileria parasites [9]. In contrast, $T$. orientalis does not induce leukocyte proliferation and is therefore referred to as a non-transforming Theileria parasite [6]. Merozoites released upon schizont lysis are infective to RBCs [6]. While T. annulata and T. orientalis merozoites efficiently multiply in RBCs, merogony in RBCs is less pronounced in T. parva [6,10]. While T. parva is endemic in eastern, central, and southern 
Africa, T. annulata is common in north Africa, southern Europe, and Asia [11], and T. orientalis has a worldwide distribution [7,8,12-18].

Most of the animals that recover from the clinical diseases caused by Babesia and Theileria parasites remain carriers of these diseases [19,20]. Subclinical infections may also be common among animals that are resistant to clinical piroplasmosis [2]. Detection of carriers and subclinical infections is essential for estimating the level of risk posed by Babesia and Theileria parasites. Therefore, data from epidemiological surveys could be useful for gauging the efficacy of the parasite control programs implemented in the past. Based on the findings of such surveys, parasite control strategies could be modified where needed. Microscopic examination of Giemsa-stained blood smears is a simple and common method for identifying blood parasites. However, because of low parasitemias at the carrier stage, microscopy may not be an effective diagnostic tool as it lacks sensitivity and specificity [21,22]. Currently, DNA detection techniques, such as PCR assays are preferable for epidemiological investigations, because these methods are specific, sensitive, and capable of detecting active infections [23].

In Egypt, cattle, buffalo, and sheep are the main source of meat, milk, and their related products. Clinical diseases caused by Theileria and Babesia species are common among the cattle and buffaloes in this country [24-26]. Disease outbreaks often lead to economic losses from reduced productivity, require costly veterinary treatment, and can result in the death of affected animals. Previously, a number of epidemiological studies of Babesia and Theileria parasites have been conducted in Egypt. B. bovis and B. bigemina have been reported in cattle, buffaloes, and ticks $[27,28]$. However, the study areas in these investigations were usually limited to one or two provinces of the country. Furthermore, most of the past epidemiological surveys have focused on either Babesia or Theileria, but studies aimed at simultaneous detection of both parasites have not been conducted. Additionally, $T$. 
orientalis, which has been reported in several countries, has never been studied in Egypt. In the present study, therefore, we conducted an epidemiological survey of $B$. bovis, B. bigemina, T. annulata, and T. orientalis, using blood-DNA samples collected from cattle and buffaloes reared in four Egyptian provinces. Sheep populations were also surveyed to investigate the possible infections with these parasite species. 


\section{Materials and methods}

\subsection{Blood sampling and DNA extraction}

A total of 594 blood samples were collected from cattle, buffaloes, and sheep during a period from August to October, 2013. In detail, cattle $(n=439)$ were sampled in four different Egyptian provinces (Menoufia, Behera, Giza, and Sohag), while blood samples were collected from buffaloes $(n=50)$ reared in the same provinces, except for Giza (Fig. 1, Table 1). Similarly, sheep $(n=105)$ were sampled in the same provinces, except for Sohag. In Egypt, livestock animals are maintained under three major management practices, intensive, semiintensive, and extensive systems. Under the intensive rearing system, large herds of exotic animals are kept within proper housing facilities, while cross-bred animals are managed by semi-intensive system. On the other hand, the extensive management is characterized by few numbers of local animals and low production inputs. Cattle in the sampled locations were maintained under intensive, semi-intensive, or extensive management systems, while the buffaloes were reared solely under the extensive system. In contrast, the sheep were managed by semi-intensive or extensive practices. All the animals were apparently healthy during the sampling period. The ages of the sampled animals ranged from $0.5-10,0.5-7$, and $1-5$ years for cattle, buffaloes, and sheep, respectively. Blood samples were collected from the tail veins of the cattle and buffaloes, while the sheep blood samples were collected from their jugular veins. Approximately $2 \mathrm{ml}$ of whole-blood was collected from each animal into a Vacutainer tube containing EDTA. The blood samples were labeled and stored at $-20{ }^{\circ} \mathrm{C}$, until the DNA extractions were conducted. DNA samples were extracted from $300 \mu$ of the blood samples using a commercial kit (Promega, Madison, WI, USA) following the manufacturer's instructions, and then stored at $-20{ }^{\circ} \mathrm{C}$ until further use. 


\subsection{PCR detections of Babesia and Theileria parasites}

Detection of B. bovis, B. bigemina, T. annulata, and T. orientalis in the DNA samples from the field-blood samples was conducted using previously described diagnostic PCR assays targeting the Rhoptry Associated Protein-1 (RAP-1), Apical Membrane Antigen-1 (AMA-1), Theileria annulata Merozoite Surface Antigen-1 (Tams-1), and Major Piroplasm Surface Protein (MPSP) genes, respectively [29-32]. While B. bovis was detected using a nested PCR assay [29], single-step PCR assays were employed to detect the other parasites surveyed [30-32]. Primer sequences and PCR cycling conditions are detailed in a previous report [33]. After gel electrophoresis of the PCR products, the products were ethidium bromide stained and visualized under UV light. Detection of a band similar to that in size of the positive control for a particular species was considered to be a positive result.

\subsection{Cloning and sequencing PCR products}

For each parasite species, PCR amplicons with high band intensities were extracted from agarose gels using a QIAquick Gel Extraction Kit (QIAGEN, Hilden, Germany), and then cloned into a plasmid vector (PCR 2.1-TOPO, Invitrogen, Carlsbad, CA, USA). For each amplicon, two clones were sequenced using an AB1 PRISM 3100 genetic analyzer (Applied Biosystems, Foster City, CA, USA).

\subsection{Sequence and phylogenic analysis}

The nucleotide sequences determined in this study were initially analyzed using the basic local alignment tool (BLAST) (http://blast.ncbi.nlm.nih.gov/). The sequence identities among the Egyptian sequences and between Egyptian and homologous sequences from other countries were determined for each parasite species using the EMBOSS NEEDLE software program (http://emboss.bioinformatics.nl/cgi-bin/emboss/needle). Phylograms were 
constructed using the nucleotide sequences generated in this study together with the homologous gene sequences reported from other countries. An online version of MAFFT software [34] was used to construct the phylogenetic trees, based on the neighbor-joining method [35] with a Jukes-Cantor substitution model [36].

\subsection{Statistical analyses}

The upper and lower limits of the confidence intervals of the positive rates were calculated for each parasite species using the OpenEpi program (http://www.openepi.com/v37/Proportion/Proportion.htm), which is based on a previously described method [37]. 


\section{Results}

The species-specific PCR assays detected all parasite species surveyed (i.e., B. bovis, B. bigemina, T. annulata, and T. orientalis) in the cattle populations (Table 1). Among the DNA samples sourced from cattle $(n=439), 86(19.6 \%)$ were positive for at least one parasite species. In cattle, the most common parasite was $T$. annulata $(9.56 \%)$, followed by $B$. bigemina $(7.97 \%)$, B. bovis $(3.18 \%)$, and T. orientalis $(0.68 \%)$. Among the provinces surveyed (Fig. 1), Behera had the highest positive rates for three parasite species, B. bovis (8.51\%), T. annulata (29.78\%), and T. orientalis (6.83), while B. bigemina was common in Giza (13.33\%). Additionally, T. orientalis was detected only among the cattle population in Behera. By contrast, all eight of the cattle sampled in Sohag were negative for all the parasites surveyed. Only B. bovis or T. orientalis were detected in the buffalo-derived DNA samples, but their rates were low (both $2 \%$ ), and each parasite species was detected in two individual animals from Menoufia. Similarly, in Behera one and two sheep were positive for B. bovis and B. bigemina, respectively. Mixed infections were limited to cattle, in which eight such animals harbored two parasite species. Among them, four samples were infected with $B$. bovis and T. annulata, while four others were positive for B. bovis and B. bigemina, B. bovis and T. orientalis, B. bigemina and T. annulata, or T. annulata and T. orientalis.

Among the positive samples, 13, 12, 14, and four of the PCR amplicons sequenced were $B$. bovis (11 cattle, one buffalo, and one sheep), B. bigemina (10 cattle and two sheep), T. annulata (14 cattle), and T. orientalis (three cattle and one buffalo), respectively. Out of these 43 PCR amplicons, the nucleotide sequences of both of the clones were identical to each other for 25 , while the sequences of remaining 18 , including $1 \mathrm{~B}$. bovis $R A P-1,3 \mathrm{~B}$. bigemina AMA-1, and 14 T. annulata Tams 1 , differed between the two clones. Therefore, a total of 61 sequences were registered in GenBank, for which the accession numbers 
AB917246 - AB917306 were obtained. The B. bovis, B. bigemina, and T. orientalis nucleotide sequences of the PCR amplicons were of the expected sizes (298, 211, and $776 \mathrm{bp}$, respectively), while the $T$. annulata sequences were 771 (AB917275-AB917298), 777 (AB917299), or 783 (AB917300-AB917302) bp in length. The identity values among the nucleotide sequences of $B$. bovis RAP-1 determined in this study (AB917246-AB917259) ranged from 99.3 to $100 \%$. Additionally, the $R A P-1$ sequences derived from a buffalo (AB917258) and a sheep (AB917259) were identical to each other and to some of those derived from cattle (AB917246-AB917251, AB917253-AB917255, and AB917257) in Egypt. Furthermore, the RAP-1 sequences from Egypt shared 99.0-99.3\% sequence identity with a previously published sequence from Sri Lanka (AB845432). The high identities among the Egyptian $R A P-1$ sequences are reflected in the phylogenetic tree, in which they were found in a single clade (clade 2) (Fig. 2).

The identity values among all 15 Egyptian B. bigemina AMA-1 sequences (AB917260-AB917274) ranged from 95.3 to $100 \%$, while the values of those from cattle (AB917263-AB917274) and sheep (AB917260-AB917262) ranged from 97.2 to $100 \%$ and 97.6 to $100 \%$, respectively. Additionally, the sheep-derived $A M A-1$ sequences (AB917260AB917262) shared $95.3-100 \%$ identity values with the AMA-1 sequences (AB917263AB917274) from the Egyptian cattle. Moreover, the AMA-1 sequences from this study also shared 97.6-100\% identity with a sequence from South Africa (KF626604). All of the Egyptian sequences were found in a single clade of the AMA-1 gene-based phylogeny (clade 2) (Fig. 3).

For T. annulata, the Egyptian Tams-1 sequences shared 87.8-100\% identity with each other and 96.0-100\% with a sequence (AF214819 in clade 3) (Fig. 4) from Mauritania. Additionally, the Tams- 1 sequences from this study shared $89.9-99.6 \%$ identity with a sequence (KJ021627 in clade 1) previously reported in Egypt. In the phylogenetic analysis, 
the Egyptian sequences were dispersed across all the clades, with the exception of clade 4 (Fig. 4).

The identities among the four T. orientalis MPSP sequences from Egypt (AB917303AB917306) ranged from 87.1 to $100 \%$. While two cattle-derived (AB917303 and AB917304) and one buffalo-derived (AB917306) sequence were classified as MPSP type 2, a single sequence from cattle (AB917305) was identified as MPSP type 1 (Fig. 5). Among the MPSP type 2 sequences, the cattle derived sequences (AB917303 and AB917304) were closely related to a sequence from China (AB571981, type 2) (99.4 and 99.9\% sequence identity, respectively), while that from buffalo (AB917306) shared a high identity value (97.8\%) with a sequence from Australia (AB520947, type 2). Additionally, the MPSP type 1 sequence from Egypt (AB917305) is close to a Chinese MPSP sequence (HQ322621), showing $99.7 \%$ identity. 


\section{Discussion}

Bovine piroplasmosis caused by Babesia and Theileria parasites has a worldwide distribution and inflicts a severe economic burden on farming communities [1]. In this study, cattle, buffalo, and sheep populations, which were bred in different geographical locations in Egypt, were surveyed for bovine parasites. Subsequently, the genetic diversity of each parasite species, based on the gene sequences determined from the PCR amplicons generated by species-specific primers, was studied.

Our findings indicate that the most common blood parasite in cattle is T. annulata. Although clinical cases of $T$. annulata are common in Egyptian bred cattle and water buffaloes [24-26,38), there are no studies detailing the detection of T. annulata from infected carrier animals. Therefore, our study should provide useful preliminary data to the policy makers associated with animal production in Egypt that could allow them to adapt better informed control strategies against this potentially harmful pathogen. Sequencing and phylogenetic analyses of $T$. annulata showed that Tams- 1 sequences are diverse in Egypt. Genetic diversity among Tams- 1 sequences is very common because of intragenic recombination, which occurs within the tick vectors [39]. Further studies aimed at understanding the relationships between genetic diversity and the biological behaviors of $T$. annulata are of interest as such investigations have not been conducted.

The second and third most common parasites in cattle were B. bigemina and B. bovis, respectively, and the rates of infections in these animals agree with those estimated in a previous study [27]. In the phylogenetic analyses, the B. bovis RAP-1 and B. bigemina AMA1 sequences were detected in single clade of their respective trees. However, the gene fragments analyzed in this study are relatively conserved among field isolates from different geographic locations [40,41]. Therefore, analyzing suitable marker genes, such as merozoite 
surface antigen genes in $B$. bovis, might provide a better picture of the genetic diversity in $B$. bovis [42-45], while identification of suitable genetic markers are essential for B. bigemina. The present study described $T$. orientalis for the first time in Egypt, and found that the parasites detected belonged to two different allelic types of MPSP; types 1 and 2. Scant literature exists on the epidemiology of $T$. orientalis in Africa. Although this parasite has been reported in Burundi, its diagnosis was based on morphological and antigenic properties [46]. Gebrekidan et al. (2014) [47] described T. orientalis in Ethiopian cattle, based on $18 \mathrm{~S}$ rRNA sequences. Additionally, a single MPSP sequence (AB016278) from Kenya falls into the MPSP type 3 clade [48]. Therefore, the detection of different MPSP types in Egypt may prove useful for furthering our understanding of the population structure of $T$. orientalis in Africa. Although the movement of $T$. orientalis-infected animals and ticks across the territorial boarders might be a possible reason for the presence of this parasite in several African countries, analysis of T. orientalis MPSP types in the this region is essential to confirm this assumption. Among the MPSP genotypes, type 2 is thought to be relatively virulent, as this type is commonly associated with clinical outbreaks and more anemic in cattle than the other genotypes [7]. Furthermore, detection of MPSP type 2 in buffaloes is particularly significant, because this allelic type has never been reported to occur in buffaloes. Thus, it appears that the involvement of buffaloes as reservoir hosts for the MPSP type 2 should not be ruled out. Nevertheless, the presence of MPSP type 2 in Egypt could indicate that the cattle populations in this country are vulnerable to clinical theileriosis as a result of infection with $T$. orientalis.

On a per district basis, Behera province had the highest parasite-positive rates in cattle among all the surveyed provinces. The humid climate in Behera, which may favor the survival of tick populations, is a possible explanation for the high rates of infection. However, additional studies to determine the population structures of the ticks in the different Egyptian 
provinces are needed to confirm this assumption. However, the small sample size of the animals surveyed in Sohag might explain why none of the parasites of interest were detected in this region.

The rates of infection with Babesia and Theileria in buffaloes and sheep in this study are low. Although some studies have described tropical theileriosis in Egyptian buffaloes [25,26], T. annulata was not detected in the buffaloes screened herein. It is possible that the small sample size is related to the low parasite-positive rates seen in the buffaloes. Interestingly, in this study, the DNA samples from sheep were infected with B. bovis and $B$. bigemina, although sheep are not a known host for these parasites. It is noteworthy that similar findings were observed in a previous study, in which Theileria equi and Babesia canis were detected in dog and horse, respectively [49]. Similarly, B. bigemina infection was reported in goats from Vietnam [50]. Although the pathobiological significance of host shifting is not known, it might be one of the survival strategies used by hemoprotozoan parasites.

In conclusion, our study detected Babesia and Theileria species in cattle, buffaloes, and sheep in several provinces of Egypt. For the first time, T. orientalis was reported in cattle and buffaloes bred in this country. These findings have economic significance and indicate the importance of introducing effective prevention and control strategies throughout Egypt to minimize the prevalence of bovine hemoprotozoan parasites, such as those investigated in this study. 


\section{Acknowledgments}

We thank Dr. Amer Hamada (Faculty of Veterinary Medicine, Sadat City University) and Ms Hiroko Yamamoto (National Research Center for Protozoan Diseases, Obihiro University of Agriculture and Veterinary medicine) for their excellent technical assistance. We also thank the owners and staff of the study farms in Egypt. This study was supported by grants from the Scientific Technique Research Promotion Program for Agriculture, Forestry, Fisheries and Food Industry, from the Japan Society for Promotion of Science (JSPS) Grantin-Aid for Scientific Research, and from the JST/JICA, Science and Technology Research Partnership for Sustainable Development (SATREPS). Ahmed Elsify was supported by a grant from Ministry of Higher Education, Egypt.

\section{References}

1. Uilenberg G. International collaborative research: significance of tick-borne hemoparasitic diseases to world animal health. Vet Parasitol 1995; 57: 19-41.

2. Bock R, Jackson L, de Vos A, Jorgensen W. Babesiosis of cattle. Parasitology 2004; 2:129 (Suppl), S247-69.

3. Zintl A, Mulcahy G, Skerrett HE, Taylor SM, Gray JS. Babesia divergens, a bovine blood parasite of veterinary and zoonotic importance. Clin Microbiol Rev 2003; 16: 62236. 
4. Homer MJ, Aguilar-Delfin I, Telford SR, Krause PJ, Persing D.H. Babesiosis. Clin Microbiol Rev 2000; 13: 451-69.

5. Everitt JI, Shadduck JA, Steinkamp C, Clabaugh G. Experimental Babesia bovis infection in Holstein calves. Vet Pathol 1986; 23: 556-62.

6. Bishop R, Musoke A, Morzaria S, Gardner M, Nene V. Theileria intracellular protozoan parasites of wild and domestic ruminants transmitted by ixodid ticks. Parasitology 2004; 129 (Suppl.); S271-83.

7. Eamens GJ, Gonsalves JR, Jenkins C, Collins D, Bailey G. Theileria orientalis MPSP types in Australian cattle herds associated with outbreaks of clinical disease and their association with clinical pathology findings. Vet Parasitol 2013; 191: 209-17.

8. McFadden AM, Rawdon TG, Meyer J, Makin J, Clough RR, Tham K, et al. An outbreak of haemolytic anaemia associated with infection of Theileria orientalis in naive cattle. $\mathrm{N}$ Z Vet J 2011; 59: 79-85.

9. Dobbelaere D, Heussler V. Transformation of leukocytes by Theileria parva and T. annulata. Annu Rev Microbiol 1999; 53:1-42.

10. Conrad PA, Denham D, Brown CG. 1986. Intraerythrocytic multiplication of Theileria parva in vitro: an ultrastructural study. Int J Parasitol 1986; 16: 223-9.

11. Lawrence JA, de Vos AJ, Irvin AD. Theilerioses. In: Coetzer JAW, Thomson GR, Tustin RC, editors. Infectious diseases of livestock, New York: Oxford University press; 1994, p. $307-41$. 
12. Altangerel K, Battsetseg B, Battur B, Sivakumar T, Batmagnai E, Javkhlan G, et al. The first epidemiological survey of Theileria orientalis infection in Mongolian cattle. Vet Parasitol 2011; 182: 343-8.

13. Altangerel K, Sivakumar T, Inpankaew T, Jittapalapong S, Terkawi MA, Ueno A, et al. Molecular prevalence of different genotypes of Theileria orientalis detected from cattle and water buffaloes in Thailand. J Parasitol 2011; 97:1075-9.

14. Khukhuu A, Lan DT, Long PT, Ueno A, Li Y, Luo Y, et al. Molecular epidemiological survey of Theileria orientalis in Thua Thien Hue. J Vet Med Sci 2011; 73: 701-5.

15. Sivakumar T, Altangerel K, Igarashi I, Xuan X, Guo G, Huang X, et al. Phylogenetic analysis of Theileria orientalis in cattle bred in Fujian province, China. J Protozool Res 2011; 21: 14-9.

16. Yokoyama N, Ueno A, Mizuno D, Kuboki N, Khukhuu A, Igarashi I, et al. Genotypic Diversity of Theileria orientalis Detected from Cattle Grazing in Kumamoto and Okinawa Prefectures of Japan. J Vet Med Sci 2011;73: 305 -12.

17. Yokoyama N, Sivakumar T, Ota N, Igarashi I, Nakamura Y, Yamashina H, et al. Genetic diversity of Theileria orientalis in tick vectors detected in Hokkaido and Okinawa, Japan. Infect Genet Evol 2012; 12: 1669-75.

18. Sivakumar T, Yoshinari T, Igarashi I, Kothalawala H, Abeyratne AS, Vimalakumar SC, et al. Genetic diversity within Theileria orientalis parasites detected in Sri Lankan cattle. Ticks Tick Borne Dis 2013; 4: 235-41.

19. Calder JA, Reddy GR, Chieves L, Courtney CH, Littell R, Livengood JR, et al. Monitoring Babesia bovis infections in cattle by using PCR-based tests. J Clin Microbiol 1996; 34: 2748-55. 
20. Medley GF, Perry BD, Young AS. Preliminary analysis of the transmission dynamics of Theileria parva in eastern Africa. Parasitology 1993; 106: 251-64.

21. Almeria S, Castella J, Ferrer D, Ortuno A, Estrada-Peña A, Gutierrez JF. Bovine piroplasms in Minorca (Balearic Islands, Spain): a comparison of PCR-based and light microscopy detection. Vet Parasitol 2001; 99: 249-59.

22. Bose R, Jorgensen WK, Dalgliesh RJ, Friedhoff KT, de Vos AJ. Current state and future trends in the diagnosis of babesiosis. Vet Parasitol 1995; 57: 61-74.

23. Mosqueda J, Olvera-Ramirez A, Aquilar-Tipacamu G, Canto GJ. Current advances in detection and treatment of babesiosis. Curr Med Chem 2012; 19: 1504-18.

24. Mahmmod YS. Molecular detection of natural Babesia bovis infection from clinically infected and apparently healthy water buffaloes (Bubalus bubalis) and crossbred cattle. $\mathbf{J}$ Buffalo Sci 2012; 1: 55-60.

25. Mahmmod YS, Elbalkemy FA, Klaas IC, Elmekkawy MF, Monazie AM. Clinical and haematological study on water buffaloes (Bubalus bubalis) and crossbred cattle naturally infected with Theileria annulata in Sharkia province, Egypt. Ticks Tick Borne Dis 2011; 2: $168-71$.

26. Osman SA, Al-Gaabary MH. Clinical, haematological and therapeutic studies on tropical theileriosis in water buffaloes (Bubalus bubalis) in Egypt. Vet Parasitol 2007; 146: 33740.

27. Ibrahim HM, Adjou Moumouni PF, Mohammed-Geba K, Sheir SK, Hashem IS, Cao S, et al. Molecular and serological prevalence of Babesia bigemina and Babesia bovis in cattle and water buffalos under small-scale dairy farming in Beheira and Faiyum Provinces, Egypt. Vet Parasitol 2013; 198: 187-92. 
28. Adham FK, Abd-El-Samie EM, Gabre RM, El-Hussein H. Detection of tick blood parasites in Egypt using PCR assay I- Babesia bovis and Babesia bigemina. Parasitol Res 2009; 105: 721-30.

29. Figueroa JV, Chieves LP, Johnson GS, Buening GM. Multiplex polymerase chain reaction based assay for the detection of Babesia bigemina, Babesia bovis and anaplasma marginale DNA in bovine blood. Vet Parasitol 1993; 50: 69-81.

30. Sivakumar T, Altangerel K, Battsetseg B, Battur B, AbouLaila M, Munkhjargal T, et al. Genetic detection of Babesia bigemina from Mongolian cattle using apical membrane antigen-1 gene based PCR assay. Vet Parasitol 2012; 187: 17-22.

31. Kirvar E, Ilhan T, Katzer F, Hooshmand-Rad P, Zweygarth E, Gerstenberg C, et al. Detection of Theileria annulata in cattle and vector ticks by PCR using the Tams1 gene sequences. Parasitology 2000; 120: 245-54.

32. Ota N, Mizuno D, Kuboki N, Igarashi I, Nakamura Y, Yamashina H, et al. Epidemiological survey of Theileria orientalis infection in grazing cattle in the Eastern Part of Hokkaido, Japan. J Vet Med Sci 2009; 71: 937-44.

33. Sivakumar T, Kothalawala H, Abeyratne AS, Vimalakumar SC, Meewawe AS, Hadirampela DT, et al. A PCR-based survey of selected Babesia and Theileria parasites in cattle in Sri Lanka. Vet Parasitol 2012; 190: 263-67.

34. Katoh K, Misawa K, Kuma K, Miyata T. MAFFT: a novel method for rapid multiple sequence alignment based on fast Fourier transform. Nucleic Acids Res 2002; 30: 305966.

35. Saitou N, Nei M. The neighbor-joining method: a new method for reconstructing phylogenetic trees. Mol. Biol. Evol 1987; 4: 406-25. 
36. Jukes TH, Cantor CR. Evolution of protein molecules. In: Munro HN, editor. Mammalian Protein Metabolism, New York: Academic Press; 1969, p. 21-132.

37. Wilson EB. Probable inference, the law of succession, and statistical inference. $\mathrm{J}$ Am Statist Assoc 1927; 22: 209-12.

38. Ghoneim AM, El-Fayomy AO. Targeting tams-1 gene results in underestimation of Theileria annulata infection in diseased cattle in Egypt. Acta Parasitol 2014; 59: 85-90.

39. Gubbels MJ, Katzer F, Hide G, Jongejan F, Shiels BR. Generation of a mosaic pattern of diversity in the major merozoite-piroplasm surface antigen of Theileria annulata. Mol Biochem Parasitol 2000; 110: 23-32.

40. Suarez CE, Palmer GH, Jasmer DP, Hines SA, Perryman LE, McElwain TF. Characterization of the gene encoding a 60-kilodalton Babesia bovis merozoite protein with conserved and surface exposed epitopes. Mol Biochem Parasitol 1991; 46: 45-52.

41. Torina A, Agnone A, Sireci G, Mosqueda JJ, Blanda V, Albanese I, et al. Characterization of the apical membrane antigen-1 in Italian strains of Babesia bigemina. Transbound Emerg Dis 2010; 57: 52-6.

42. Genis AD, Mosqueda JJ, Borgonio VM, Falcón A, Alvarez A, Camacho M, et al. Phylogenetic analysis of Mexican Babesia bovis isolates using msa and ssrRNA gene sequences. Ann N Y Acad Sci 2008; 1149: 121-5.

43. Altangeral K, Sivakumar T, Battsetseg B, Battur B, Ueno A, Igarashi I, et al. Phylogenic relationship of Mongolian Babesia bovis isolates based on the merozoite surface antigen (MSA)-1, MSA-2b, and MSA-2c genes. Vet Parasitol 2012; 184: 309-16. 
44. Sivakumar T, Okubo K, Igarashi I, de Silva WK, Kothalawala H, Silva SS, et al. Genetic diversity of merozoite surface antigens in Babesia bovis detected from Sri Lankan cattle. Infect Genet Evol 2013; 19: 134-40.

45. Tattiyapong M, Sivakumar T, Ybanez A.P, Ybanez RH, Perez ZO, Guswanto A, et al. Diversity of Babesia bovis merozoite surface antigen genes in the Philippines. Parasitol Int 2014; 63: 57-63.

46. Kiltz HH, Uilenberg G, Franssen FF, Perié NM. Theileria orientalis occurs in Central Africa. Res Vet Sci 1986; 40: 197-200.

47. Gebrekidan H, Hailu A, Kassahun A, Rohoušová I, Maia C, Talmi-Frank D, et al. Theileria infection in domestic ruminants in northern Ethiopia. Vet Parasitol 2014; 200: $31-8$.

48. Kawazu S, Kamio T, Kakuda T, Terada Y, Sugimoto C, Fujisaki K. Phylogenetic relationships of the benign Theileria species in cattle and Asian buffalo based on the major piroplasm surface protein (p33/34) gene sequences. Int J Parasitol 1999; 29: 6138.

49. Criado-Fornelio A, Martinez-Marcos A, Buling-Saraña A, Barba-Carretero JC. Molecular studies on Babesia, Theileria and Hepatozoon in southern Europe. Part I. Epizootiological aspects. Vet Parasitol 2003; 13: 189-201.

50. Sivakumar T, Lan DT, Long PT, Yoshinari T, Tattiyapong M, Guswanto A, et al. PCR detection and genetic diversity of bovine hemoprotozoan parasites in Vietnam. J Vet Med Sci 2013; 75: 1455-62. 


\section{Figure legends}

Fig. 1. Sampling locations in Egypt. Blood samples were collected from animals reared in Menoufia (M), Behera (B), Giza (G), and Sohag (S), as indicated by bullet points.

Fig. 2. Phylogenic tree of the B. bovis RAP-1 gene. The neighbor-joining tree [35] was constructed based on the Jukes-Cantor substitution model [36] using the MAFFT program [34]. The nucleotide sequences determined in this study are shown in boldface type letters. Bootstrap values are provided at the beginning of each branch. Note that the Egyptian $R A P-1$ sequences are found in a single clade.

Fig. 3. Phylogenic tree of the $B$. bigemina $A M A-1$ gene. The neighbor-joining tree was constructed based on the Jukes-Cantor substitution model using the MAFFT program. The nucleotide sequences determined in this study are shown in boldface type letters. Bootstrap values are provided at the beginning of each branch. Note that the Egyptian $A M A-1$ sequences are found in a single clade.

Fig. 4. Phylogenic tree of the T. annulata Tamsl gene. The neighbor-joining tree was constructed based on the Jukes-Cantor substitution model using the MAFFT program. The nucleotide sequences determined in this study are shown in boldface type letters. Bootstrap values are provided at the beginning of each branch. Note that the Egyptian Tams-1 sequences are found in multiple clades.

Fig. 5. Phylogenic tree of the $T$. orientalis MPSP gene. The neighbor-joining tree was constructed based on the Jukes-Cantor substitution model using the MAFFT program. The 
sequences determined in this study are shown in boldface type letters. Bootstrap values are provided at the beginning of each branch. Note that the Egyptian MPSP sequences fall into MPSP type 1 and 2 clades. 


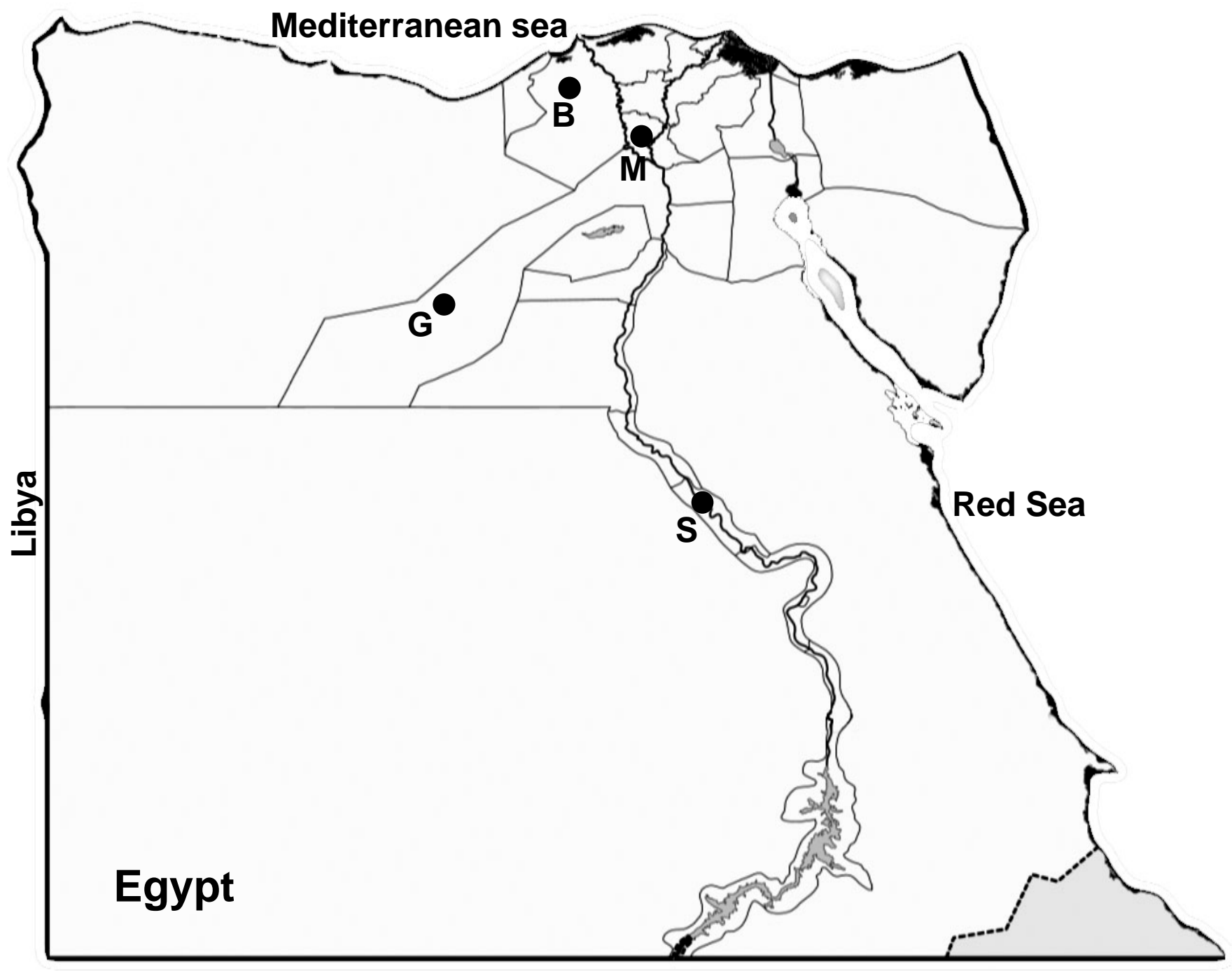

Sudan

Fig. 1 


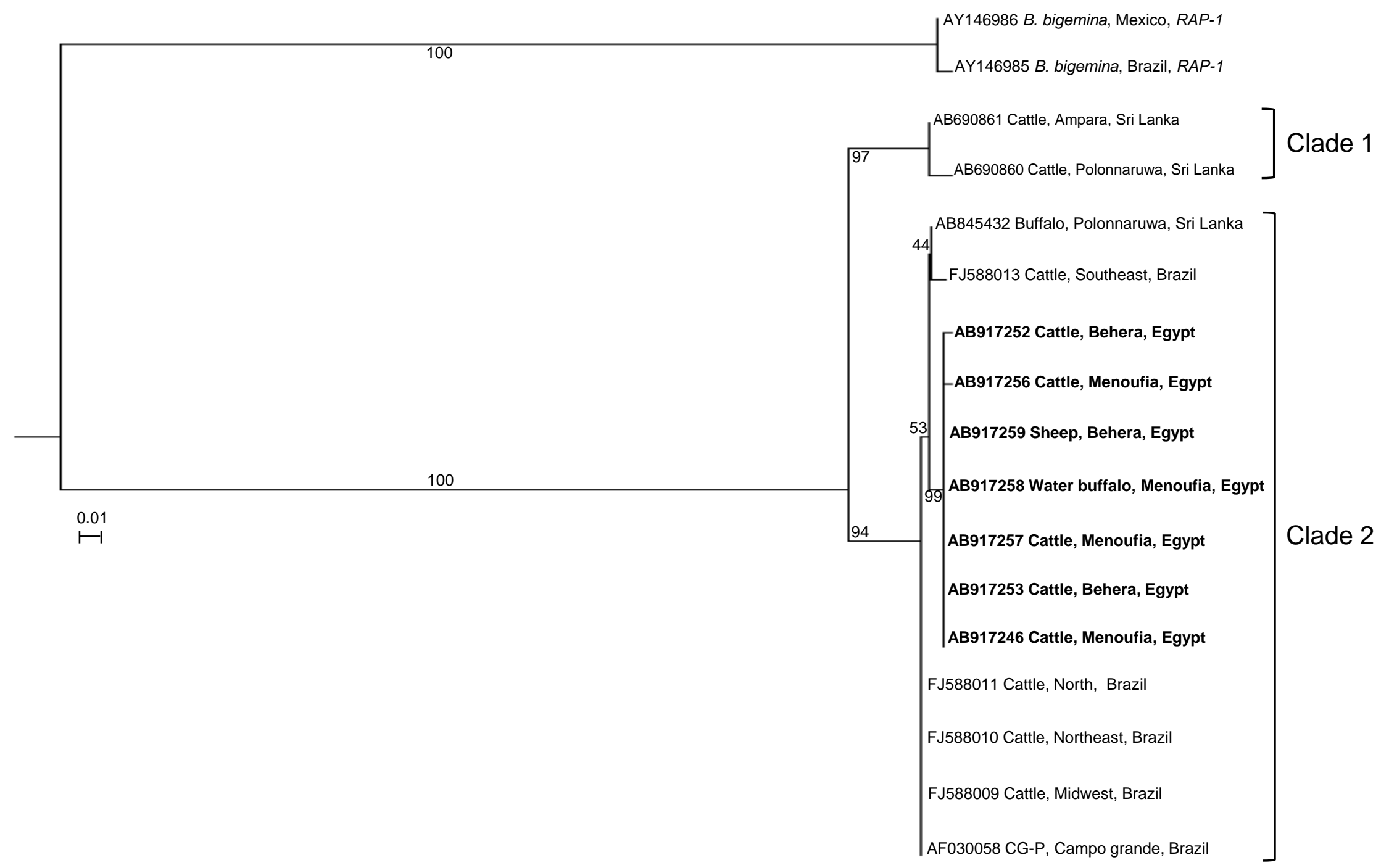

Fig. 2 


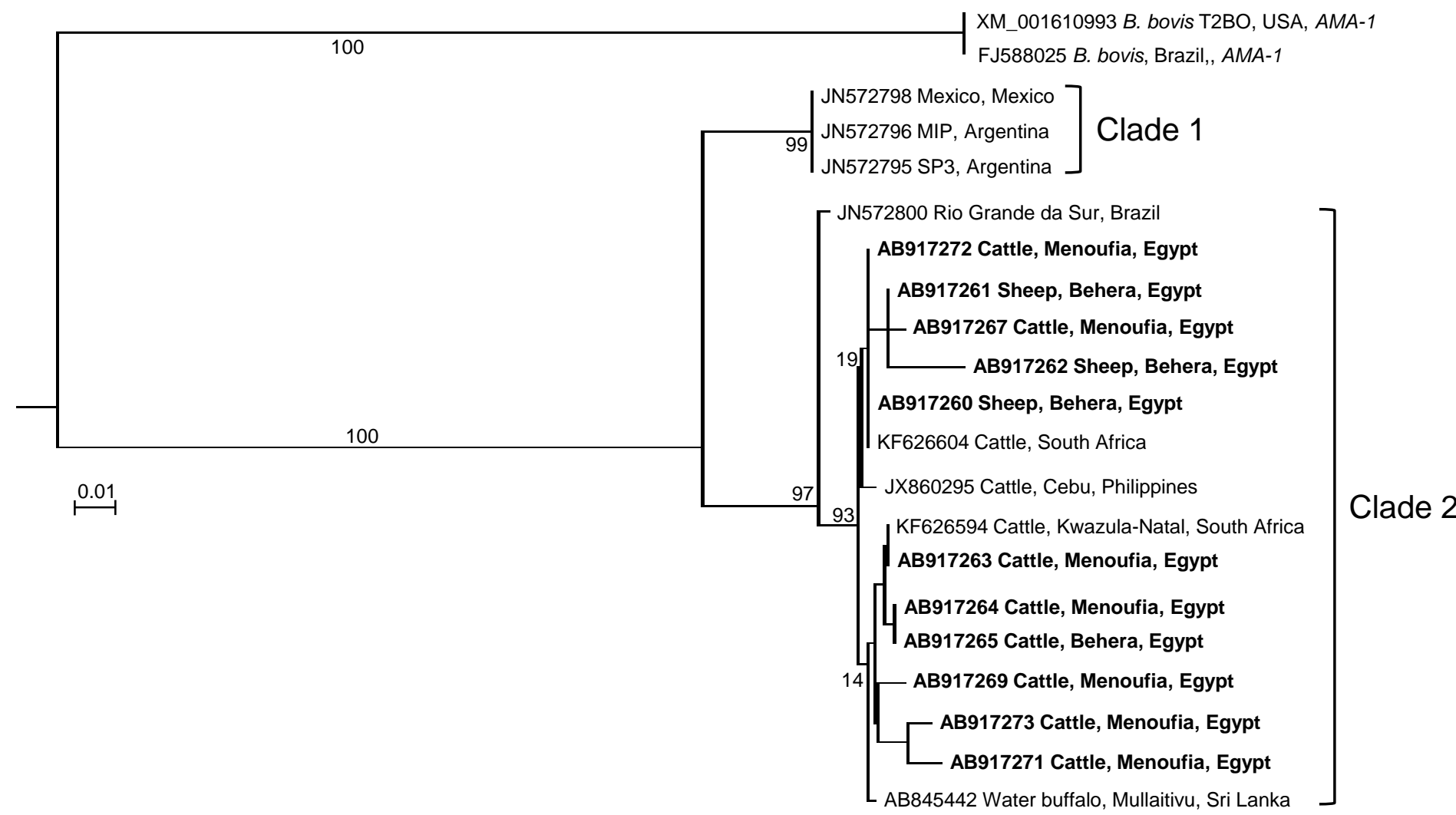

Fig. 3 


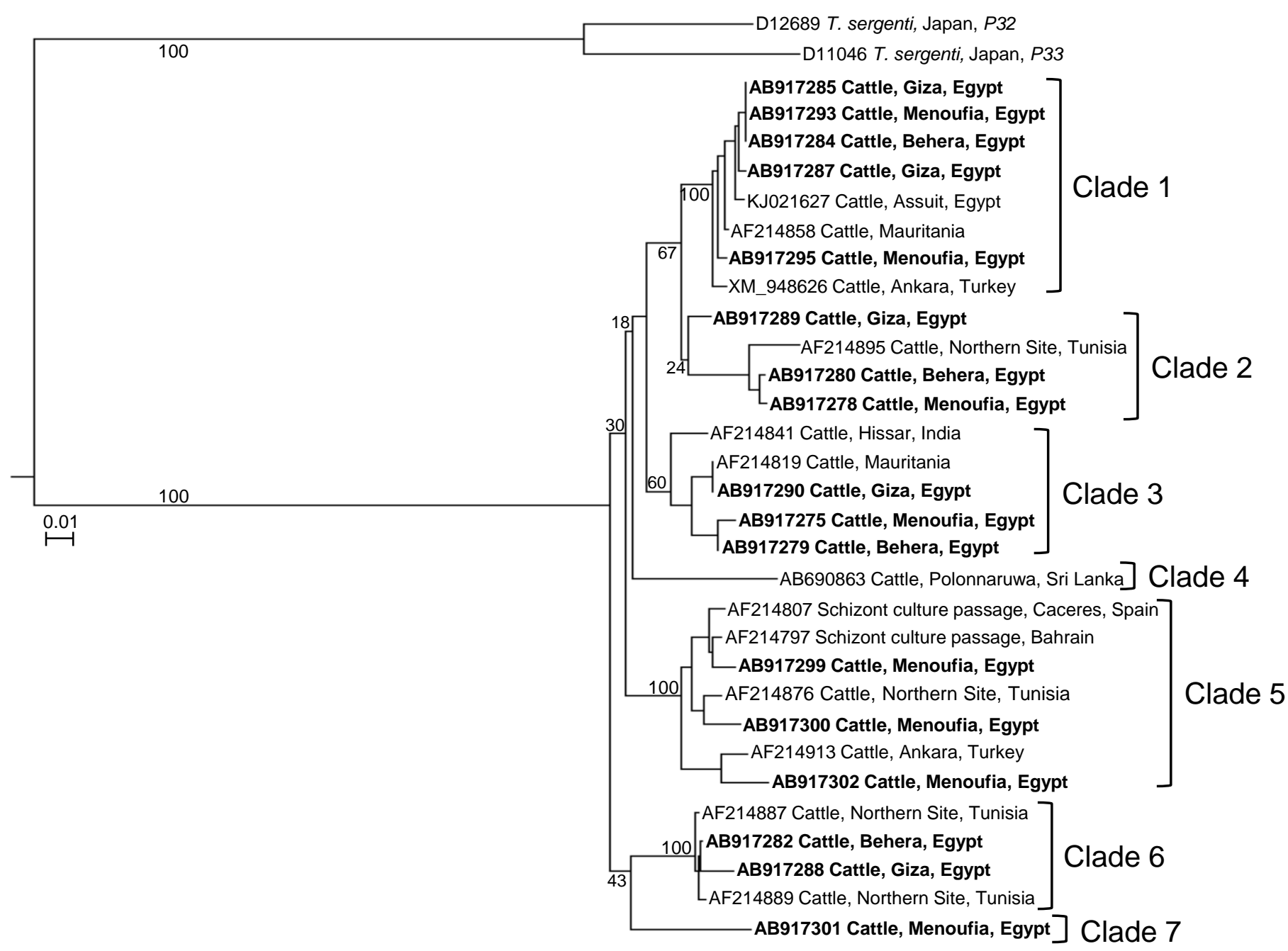

Fig. 4 
Z48738 T. annulata, Ankara,Tams1

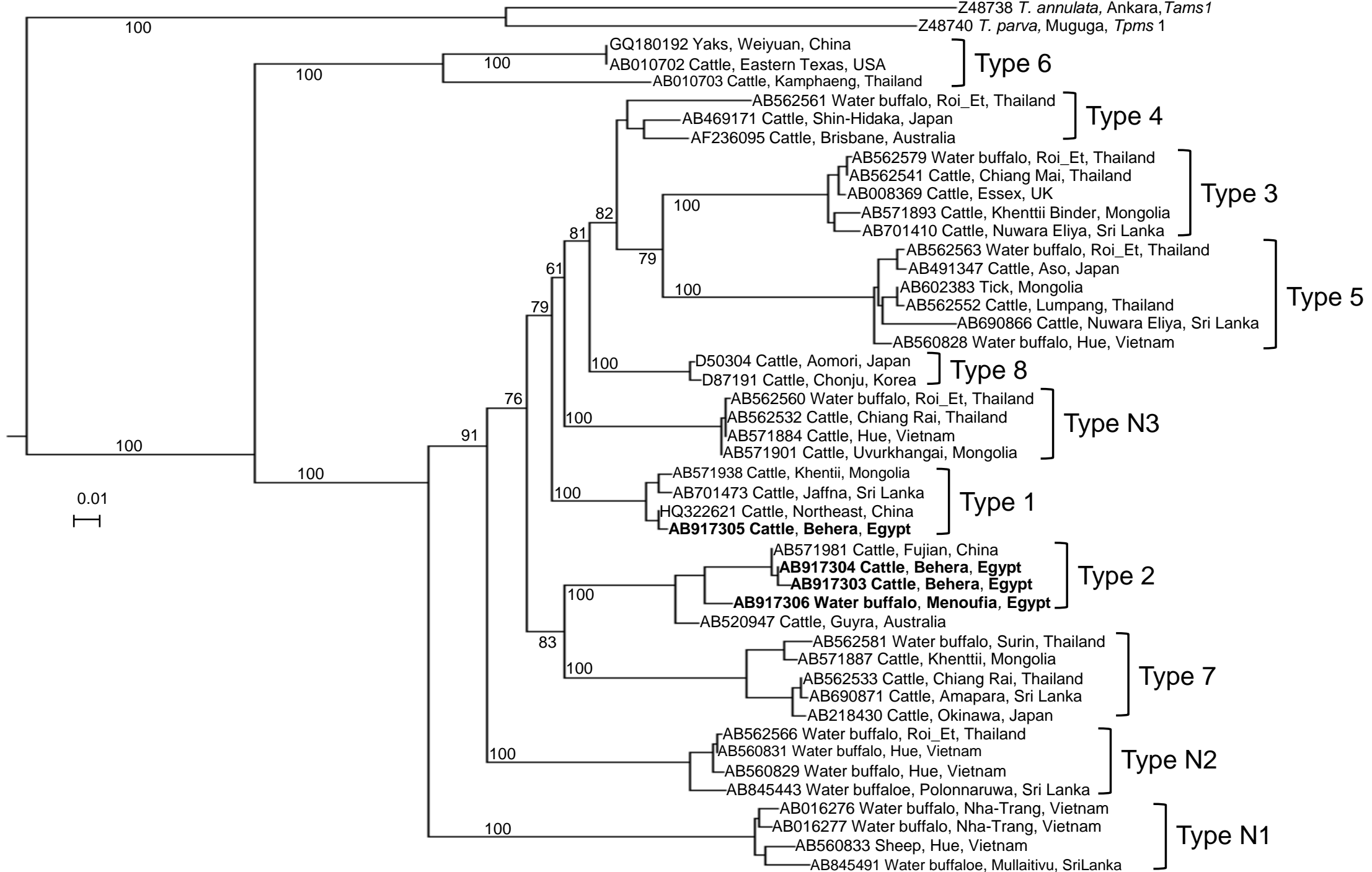

Fig. 5 
Table 1. PCR detection of B. bovis, B. bigemina, T. annulata, and T. orientalis in cattle, buffaloes, and sheep

\begin{tabular}{|c|c|c|c|c|c|c|c|c|c|c|}
\hline \multirow{2}{*}{$\begin{array}{l}\text { Animal } \\
\text { type }\end{array}$} & \multirow{2}{*}{ Provinces } & \multirow{2}{*}{$\begin{array}{c}\text { No. of } \\
\text { Samples }\end{array}$} & \multicolumn{2}{|c|}{ B. bovis } & \multicolumn{2}{|c|}{ B. bigemina } & \multicolumn{2}{|c|}{ T. annulata } & \multicolumn{2}{|c|}{ T. orientalis } \\
\hline & & & No. positive & $\%\left(\mathrm{Cl}^{\mathrm{a}}\right)$ & No. positive & $\%(\mathrm{Cl})$ & No. positive & $\%(\mathrm{Cl})$ & No. positive & $\%(\mathrm{Cl})$ \\
\hline \multirow{5}{*}{ Cattle } & Menoufia & 354 & 9 & $2.54(1.34-4.76)$ & 27 & $7.62(5.2-10.87)$ & 24 & $6.77(4.59-9.88)$ & 0 & 0 \\
\hline & Behera & 47 & 4 & $8.51(3.36-19.93)$ & 4 & $8.51(3.36-19.93)$ & 14 & $29.78(18.65-43.98)$ & 3 & $6.83(2.19-17.16)$ \\
\hline & Giza & 30 & 1 & $3.33(0.59-16.67)$ & 4 & $13.33(5.31-29.68)$ & 4 & $13.33(5.31$ - 29.68) & 0 & 0 \\
\hline & Sohag & 8 & 0 & 0 & 0 & 0 & 0 & 0 & 0 & 0 \\
\hline & ( Total ) & 439 & 14 & $3.18(1.90-5.28)$ & 35 & $7.97(5.78-10.89)$ & 42 & $9.56(7.15-12.68)$ & 3 & $0.68(0.23-1.99)$ \\
\hline \multirow{4}{*}{ Buffalo } & Menoufia & 33 & 1 & $3.03(0.53-15.63)$ & 0 & 0 & 0 & 0 & 1 & $3.03(0.53-15.32)$ \\
\hline & Behera & 3 & 0 & 0 & 0 & 0 & 0 & 0 & 0 & 0 \\
\hline & Sohag & 14 & 0 & 0 & 0 & 0 & 0 & 0 & 0 & 0 \\
\hline & ( Total ) & 50 & 1 & $2.00(0.35-10.49)$ & 0 & 0 & 0 & 0 & 1 & $2.00(0.35-10.49)$ \\
\hline \multirow{4}{*}{ Sheep } & Menoufia & 25 & 0 & 0 & 0 & 0 & 0 & 0 & 0 & 0 \\
\hline & Behera & 27 & 1 & $3.70(0.65-18.25)$ & 2 & $7.40(2.05-23.37)$ & 0 & 0 & 0 & 0 \\
\hline & Giza & 53 & 0 & 0 & 0 & 0 & 0 & 0 & 0 & 0 \\
\hline & ( Total ) & 105 & 1 & $0.95(0.16-5.19)$ & 2 & $1.90(0.52-6.68)$ & 0 & 0 & 0 & 0 \\
\hline
\end{tabular}

\footnotetext{
a $95 \%$ confidence interval
} 

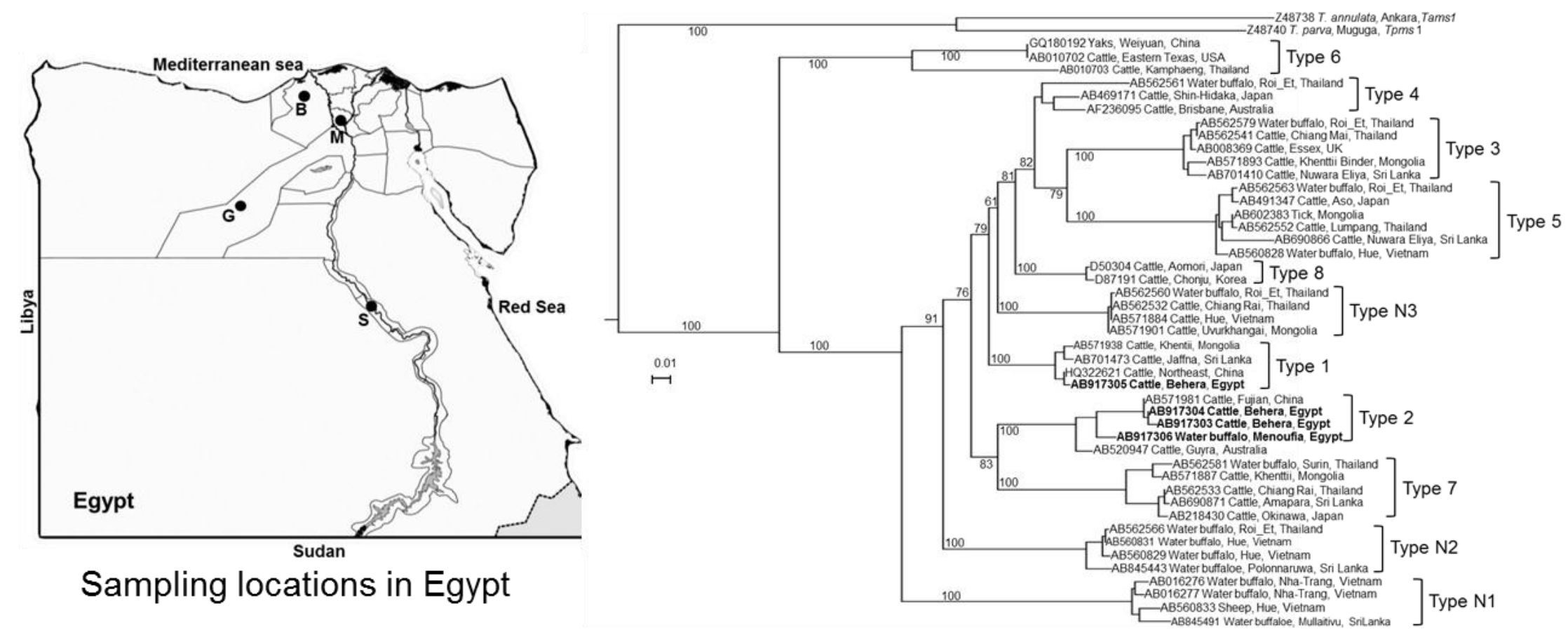

Phylogeny of $T$. orientalis MPSP 